\title{
Secondary Victimization from the Perspective of the Rights of the Child and Adolescent
}

\section{Mendes de Medeiros A0*}

Postgraduate in Labor Law and Social Security, Researcher in the legal area, University of the West of Santa Catarina, Brazil

*Corresponding author: Aline Oliveira Mendes de Medeiros, Activist lawyer since 2016, postgraduate in Labor Law and Social Security, Researcher in the legal area, University of the West of Santa Catarina. Author of the Right in Study Blog, and of the book The Promotion of Fundamental Human Rights through the Military Police, Brazil, Email: linny.mendes@hotmail.com

\section{Abstract}

This article aims to analyze the victim of the offense of rape of a vulnerable person from the perspective of his re victimization through the criminal prosecution process, since he is victimized for the first time through the criminal act and becomes victimized again in the course of the course of the process, since it often results in the innocence of the accused, when he was, in fact, actually guilty. Or, someone who has been victimized many times ends up becoming a victimizer, using the fact of having been the target of a crime to act on other individuals, abusing them. Therefore, through the inductive method, he seeks other means of seeking the unfolding of facts, in order to bring maximum effectiveness and veracity to the judicial system, avoiding errors and false convictions.

Keywords: Victimization; Rape; Victimizer; Victimized; Carnal Conjunction; Cheer

\section{Introduction}

This work aims to address the issue of secondary victimization suffered by children through the rape of the vulnerable, in order to alert the legislator about the negative impact that the inquisition system has caused on them, to the detriment and disrespect for principles inherent to human beings, as the dignity of the human person. The method used in this research will be inductive. The project will be carried out through doctrinal research, explaining the opinion of authors on the subject, focusing on the respective traumas that such a system causes in children.

First, the normative historical evolution suffered by the child and adolescent will be carried out, then the theme will be addressed by explaining the issue of sexual violence in the intra-family and extra-family environment, which result in the psychological shock called secret and addiction syndrome . Next, the types of victimization whose child will be exposed will be explained, and their possible mental consequences, the designation of the offense of rape will also be expressed according to its doctrinal classification, with a view to a complete understanding of the subject mentioned here.

Ending with a broad explanation regarding the procedural process to which the child is submitted, both at the time of the witness's hearing and during the process, aiming at the psychological damage, sometimes irreversible to the human being, to which the child is exposed due to the 
procedural bureaucracy, which submits it to the status of a thing, throwing its dignity away as well as its credibility in the judiciary-. Finally, it will be explained about the undamaged testimony project, which seeks to reduce the incidence of victimization in juvenile victims, as well as speed up the process, in order to expose the child as little as possible to the impacts of the current penal system, valuing the dignity of the human person, with a view to the fact that the child even having been exposed to such a barbaric crime, can continue his personal life shaken as little as possible, undergoing psychological consultations when necessary, so that the their social life is preserved and their rights enforced.

\section{Evolution of Child and Adolescent Rights}

With regard to juvenile crimes, in order to have an accurate understanding in the legal sphere, it is necessary to address, even if succinctly, the normative historical evolution related to minors, including their lack of normative protection, from medieval times to the middle of the 20th century, therefore, it is highlighted the fact that the trajectory of the normative juvenile rights was marked by violence, in this perspective, Mendez [1] and Fachinetto [2] stand out that it is possible to divide this evolution into three stages, being the same of undifferentiated criminal, protective and juvenile criminal character, which will be scrutinized for a better understanding of the social and normative evolution related to them. In this regard, the jurist Ubaldino Calvento [3]:

It recognized the existence of three schools in the I IberoAmerican Congress of Juvenile Judges held in Nicaragua, defining them as:

$>$ Doctrine of full protection -based on the rights of children, recognized by the UN, the law would ensure the satisfaction of all the needs of minors, in its general aspects, including those related to health, education, recreation, professionalization, etc.

$>$ Doctrine of the Minor's Criminal Law -only from the moment the minor commits an act of delinquency is in the interest of the law.

$>$ Intermediate Doctrine of the Irregular Status -minors is subjects of law when they are in a state of social pathology, legally defined. It's the Brazilian doctrine

Based on the Code of Hammurabi (1,600-1,700 BC), in so-called traditional societies there was no significant distinction between childhood and adulthood; schools were attended by all ages. It is verified, in this historical-cultural moment, that the penalties were inhuman and the child was objectified, for example, the penalty of the adoptive son who wished to return to the paternal house, was to extract his eyes. With the advent of the XII Tables Law, the son was seen as an object, with the father holding capital power over the son, allowing him to trade or decide on his life or death. In ancient Greece, disabled children were eliminated, including, both in Rome and in Greece; the father had exclusive power over the family, being lawful for him to decide on punishment, imprisonment or even the exclusion of children or women from the family.

In Brazil, the carelessness with the child was of the same proportion, and in the first ships in Portugal, only men and children came, who were responsible for providing services during the voyage, such as sexual favors, and, in cases of storms, were the first charge thrown overboard. With the Felipine Ordinances (1603), there is now a slight humanism related to minors, thus classified those up to 21 years of age. even though, legitimately, minors under 7 years of age were unimputable, having their acts equated with that of animals, for young people between 7 and 17 years of age, only capital punishment was prohibited, and for minors between 17 and 20 years of age, there was a decrease in penalty in relation to adults, according to criteria such as the mode of execution, the circumstances of the crime, the victim and the malice of the perpetrator. In the year 1780, in England, the child could be sentenced to hanging in more than 200 criminal types. Only in 1871 did society start caring about children, and the Society for the Prevention of Cruelty to Children was founded in New York [4].

In 1889 , Brazil began to exercise intra-family social control, creating the Rio de Janeiro Institute for the Protection and Assistance of Children. With independence, in 1822, the country formulates new legislation such as the Federal Constitution of 1824 and codifying the fact that the sentence could not exceed 17 years of imprisonment, and would be served in a correctional facility different from those of adults. At the end of the 19th century, the Republican Period begins in Brazil, bringing with it the Penal Code of the United States of Brazil of 1890, which differs from the previous code by innovating in its Article 27, which provided for the nonimputability for 9 years and young people between 9 and 14 years old would be subject to relative non-imputability, where they would only be convicted if the magistrate understood that there was discretion on the part.

In the beginning of the 20th century, several international norms were created, such as "The Geneva Declaration of 1924, in which the need to provide children with special protection is urged; the 1948 Universal Declaration of Human Rights; the Covenant of San José de Costa Rica of 1960 and, in particular, the Universal Declaration of the Rights of the Child of 1959, famous for spreading the policy of 'The Best Interested of the Children" [5]. This brings as an effect to Brazil, the enactment of Law 4.242, of January 5, 1921, which in its Art. 3, §17 increases the non-imputability for 14 years, regardless of discernment factors, being reaffirmed by Art. 
27, § 1 of Decree 22,213, of December 14, 1922.

At that time, from June 29th to July 1st, 1911, takes place in Paris, the International Congress of Minors, and the Genoa Declaration of the Rights of the Child, worn by the League of Nations in 1924. Driven, Brazil creates Decree 17,943-A, called the Code of Minors of Brazil or Mello Mattos Code, which reaffirms the non-imputability of minors under 14 and those over 14 and under 18 would have the right to special criminal proceedings. In 1940, the Penal Code was created, establishing criminal non-imputability up to the age of 18 , listed in Article 23.

In line with Hungary [6] and Lombroso's thesis [7], it appears that childhood is the main responsible for the psychological development of the human being, therefore, this period is of fundamental importance in the construction of the child's character. It is at this moment that the person's formation is due, and thus, the decline of the minor to criminality or not due to the precarious environment where they live, the education they receive and the family guidance they receive, in this way, at the time they society and the family fail, it is up to the State to guarantee adequate treatment to the minor, through pedagogical methods.

Derived from the ineffectiveness of this legal system, the Social Statute of Children and Youth emerged in 1951, bringing with it a humanitarian system due to the international influence of the post-war period. In 1964, the Military Government creates the PNBEM (National Policy for the Welfare of Minors), which culminates in the creation of FUNABEM (State Foundation for the Welfare of Minors), an agency for the social control of crime and child marginality, with SAM's substitute objective. In 1967, State Law 1534 created the FEBEM for the state of Guanabara, whose purpose was to provide assistance to minors in an irregular situation, preventing marginalization and promoting their promotion to the social environment.

In turn, with the same protective purpose, the state of Rio de Janeiro created FLUBEM, which, with the merger of these two states, also formed the institutions, which became known as FEEM. Immediately, in 1979, the new Minors Code of 1979, which adopted the doctrine of "irregular status" and brought the adolescent as a guardian of the State, giving legitimacy to state intervention for cases of minors who were in an irregular situation, such as abandoned, exposed or marginalized, who were then removed from their families and kept with minor offenders, where they received hospitalization therapy, whose measure was to deprive them of their freedom without a fixed period, which was responsible for legitimizing a policy of social control, surveillance and repression. According to Saraiva [8], the FEBEM system was constituted by $80 \%$ of innocent youths, that is, the system imprisoned innocent minors, in an inversion of the norm, because instead of protecting children, the State simply removed them from social life.

The state represented an authoritarian regime acting to violate and restrict human rights, characterized by racial and gender discrimination, regressing the minor to objectification and the object of repression, based on prejudices and stereotypes. As a means of maintenance, this system was organized in order to control and oppress associative entities and social movements, the State was responsible for convincing the population and minors themselves that they were responsible for their irregular condition, without considering the circumstances of social inequalities and of the despot economic culture that was established, a situation to which the State pejoratively referred to as minorism. The doctrine of the irregular situation being discredited, the doctrine of integral protection, supported by the UN, was increasingly receiving adherents, aware of the need for a jurisdiction that respected and protected human rights and the dignity of the human person.

In this sense, Leite, cited in the article by Custódio AC, et al. [9], advises that, in analyzing the system of the 1979 Minors Code, it is possible to state that every young person from a lowly class was considered to be in an "irregular situation", which made him an object of guardianship of the State and not subject of rights, and automatically, it made legitimate the State's action through the Juvenile Judge, to include him in the assistance regime adopted by the same. In 1984, Francisco de Assis Toledo brought with his doctrine the Penal Reform of 1984, through Law 7,209/84. This historical development is followed by the creation of the 1988 Federal Constitution, where in its 5th article it guarantees the rights: life, liberty and equality.

And in 1990, Law 8069/90 appears, called the Child and Adolescent Statute, putting an end to the theory of irregular situation, which verified the situation of the minor through protective eyes, giving them reasons for their crimes based on the situation. In which they lived, that is, considered until now as the protective phase of minors. In this sense, in its regulations the $\mathrm{CF} / 88$ brought in its art. 227, caput, that it is the duty of society, the State and the family to ensure rights such as life, health, food, in addition to the biological, psychological and social protection of children and adolescents. The ECA -Law 8.069/90 -is based on the premise of the young person as a subject of rights and obligations, being then held responsible for the acts that they practice, and then having to undergo re-socialization, through protective measures contained in the statute.

Also in 1990, through Decree No. 15,950, FEEM was renamed Fundação Recanto, due to the fact that ECA changed 
the nomenclature from "minor" to child and adolescent, later in 1995 renamed FIA/RJ "In 1993 and 1996, Law No. 8,742/93 -Organic Law of Social Assistance (LOAS) and Law No. 9,394/96 -Law of Guidelines and Bases of National Education (LDB) appear, respectively, on which the main instruments of effectiveness of the ECA: The Child and Adolescent Law Councils, the Guardianship Councils and the Public Policy Sectors" [10].

In this logic, it is noticeable that the social policy applied to young people, successively, is out of the worst kind, resulting in disenfranchised and denigrated youths subjected to private imprisonment and restricted from their existential freedom, which derived from the current protective legislation of the State, which sees the child and the adolescent as a fully-fledged citizen, aiming at a priority protection for these young people, coming from $\mathrm{CF} / 88$, Article 227, caput, which defends the Principle of Priority, and Best Interest, due to the fact that they are under development of their personality and character, recognizing that these young people are primarily victims of a system, without giving in to the idea of juvenile impunity.

\section{Sexual Violence in the Intra-Family and Extra-Family Environment}

It is noticeable that violence intrinsically follows the evolution of society; it is even verifiable that it is part of everyday life, being present since the beginning of time in the social context, being therefore implanted in civilization, constituting roots in culture, which represents a strong threat to humanity. In this context, we will focus on family violence against children and adolescents, which, according to Art. 1 of the ECA refers to people under 18 years old, in view of that, according to Azevedo and Guerra [11], domestic violence is thus defined:

... Every act or omission committed by parents, relatives or guardians against a child and/or adolescent who, being capable of causing the victim physical, sexual and/or psychological pain or damage implies, on the one hand, a transgression of power/duty of adult protection. On the other hand, it leads to the reification of childhood, that is, to a denial of the right that children and adolescents have to be treated as subjects and people in a peculiar condition of development.

At this point, the differentiation of intra- and extrafamily sexual abuse is highlighted, with the first being sexual abuse carried out by people with a family relationship, or responsibility for the vulnerable - the most common, representing $80 \%$ of cases, and the second refers to sexual abuse by people without an affective or kinship bond with the victim, normally being related to commercial sexual exploitation. There are even statements that equate these two meanings, according to ABRAPIA [12].

This phenomenon of violence against children and adolescents, quite abstruse and multifaceted, reaches all social or socio-educational levels, as it addresses several forms, some mentioned, and among these forms, here we place special relevance and gravity to the crime of violence sexual, which in the conception of the authors Azevedo and Guerra [11], is characterized by: "[...] every sexual act or game, heterosexual or homosexual relationship between one or more adults with a child or adolescent, with the purpose of stimulating sexually this child or adolescent or use it to obtain a sexual stimulation on him or another person".

Or, according to Azevedo and Guerra [11], it is the involvement of children and adolescents in sexual activities, for which their mental development is incomplete or reduced, so that they are unable to discern the consent and meaning of such an attitude that violate social and family rules, including incest, which is sexual contact between consanguineous or related relatives, pedophilia and violent sexual abuse. In this sense, it is verifiable that intra-family child and adolescent sexual abuse has large proportions of seriousness and social risk, since due to the durability and habituality that usually exists in this criminal practice, the damage suffered by the victims is not only physical but also psychological, often irreversible. Going against the Magna Carta, which in its Art. 5 , provides guarantees to fundamental rights, and then the crime, due to its relevant value and social aversion, criminally typified as rape of the vulnerable, expressed through Art. 217-A of the CP.

Regarding the legal classification of this crime, in Brazil, the first legislation to provide for the presumption of violence was the 1890 Code, in article 272, assuming violence when the sexual act was committed against a minor under 16 years of age [13]. In the understanding of the same author, the 1940 Code kept the previous wording, but reduced the age group to 14 years, in art. 224 also added the hypothesis that the victim who has, for any reason, difficulty in offering resistance, or who is alienated or mentally retarded, also fits into this criminal modality.

With the enactment of Law 12.015/2009, the entire previous text is revoked, defining this crime as "rape of the vulnerable", art. 217-A of the CP. One of the main concerns of the legislator with the enactment of this law was the protection of minors under 18 years old against sexual crimes [14]:

... And the proliferation of child prostitution and various other forms of sexual exploitation. The repression of the sexual exploitation of minors has been the object of several 
international treaties and conventions, both because of the relevance of the legal interest, and also in view of the international dimension that the trafficking of minors for sexual purposes has taken on.

In this logic, this crime is confronted with universal human rights, as it is noted that this crime exceeds any limit or rule, whether social, cultural, legal or family, seriously harming morals and good customs in a perverse way, as it supersedes the guiding principles of the family, in a reprehensible and degrading way. The consequences of this crime are different depending on each vulnerable person, but they can occur, according to Zavaschi Ml, et al. [15],

... Negative manifestations such as personality disorder, self-mutilation, attempted suicide, depression, isolation, nightmares, fears, anxieties, introduction of objects into Organs sexual organs, excessive masturbation, "knowledge of sexuality inappropriate for their age, seductive behavior", among others.

It can happen that in the course of violence the child may be injured, making the crime identifiable, however, this is not always possible, making the child's word of fundamental value.

Also cited in that article [16], states that the aggressors' preference for children is due to the weakness in obtaining resistance from the victims and the vulnerability of being deceived and intimidated, together with factors such as culturally inserted respect in relation to the adult's authority, a fact that makes the relationship more lasting due to the minors' lack of reaction capacity. Similar to the circumstances of abused children, the author highlights the family as the main starting point, since the lack of attention dispersed in the child, the lack of affection, love; make them needy and vulnerable to attacks. Accordingly [17], the geneticist Renato Zamora Flores, in an interview for the article "Inocência Violada" reports:

...The frequency of incestuous relationships between most species of birds and mammals and of behavioral genetics is only $1 \%$ to $2 \%$ and the estimate for humans is $20 \%$. In some animal families, females stop ovulating when there are only relatives available for procreation, driven by the instinct that equal sex weakens the species and reduces the chances of survival. Incest is essentially human and that's what seems to scare people.

\section{The Secret Syndrome and the Addition Syndrom}

Such a situation, when it occurs in the family environment, often results in the phenomenon known as the secret syndrome, which consists of the concealment of the crime by the victim and family members, motivated by the preservation of the family environment, the lack of evidence, lack of credibility, too, due to threats, guilt, denial and fear of punishment for the act performed. It is noticed that when the abuser lives with the person on a daily basis, the child finds it more difficult to report the facts, because it makes it easier for the author of the cases to maintain the aggressions and repeated threats, this combined with the issue that the person is usually someone of the victim's trust, like the father, for example, for whom the child feels affection, and fear of destroying the home and causing the family's unhappiness.

It is noteworthy in this matter that the fact that the author makes the relationship lasting, causes the child to be discredited and feel a more evident psychological fear and guilt, culminating in the denial of the facts and the victim's silence. It is also notable in these issues that in most of the events, the child only wants the abuse to stop, sacrificing himself for the family. At this point, Patricia Rangel [18] states that the greatest difficulty the victim encounters in reporting the facts is when it comes to male minors who are abused by adults of the same sex as hers, she also adds a little to this. Index of denunciation of episodes in this sense.

In turn, the addiction syndrome is psychologically processed in the abuser, where he is aware of the crime he is committing, but loses control of his actions, being driven by the repeated impulse to repeat the conduct, for his satisfaction as in a kind of addiction.

Addiction aspects can also occur in victims, when they start using drugs such as alcohol or cigarettes, in an attitude of early maturity. This cycle of rape has even more disastrous consequences when the perpetrator is the victim's father, as the victim grows up without proper discernment of the incest relationship, which makes it easier for the victim to commit the crime in the future. Psychological support for both the perpetrator and the victim is necessary to completely solve the problem.

\section{Primary, Secondary and Tertiary Victimization}

Victimization is the opposite physical or psychological consequences that a negative event caused. It can be divided into three:

$>$ Primary victimization, the first step, as it consists in the experience of abuse itself, that is, it is the negativity caused by the crime, this process takes place at the moment when the abuser coerces the victim to perform the sexual act, which without the physical or moral coercion she would not have practiced.

$>$ Therefore, secondary victimization or re victimization, 
which occurs in a second moment through the postcrime, is usually related to the recollection of the crime, public exposure, and even with institutional violence, through the moment of the victim's inquiry into the criminal proceedings. In this regard [19]:

Victims of crime and victims of abuse of power, and often also their families, witnesses and other people who come to their aid, unjustly suffer loss, damage or loss and may, in addition, be subjected to additional ordeals when they collaborate in the pursuit of offenders.

$>$ On the other hand, tertiary victimization arises from the victim's own behavior, as the victim absorbs the victimization suffered previously and starts to relate to the social environment in a vengeful way, about which, lectures Beristain [20]:

When someone, for example, aware of their primary or secondary victimization, calls for a paradoxically successful outcome in a sense (media fame, applause from extremist groups, etc.), he deduces that he should accept this new image of itself (a), and decides, through this role, to avenge itself on the injustices suffered and its victims (sometimes legal).

In this approach, from victimized the victim starts to victimize, in other words uses the open wounds in his body and psychological to open, in the same way as in itself or even worse, by means, often strategic, in other victims the same wounds by which it had been wounded, blending into the criminal type.

\section{The Offense of Rape and its Doctrinal Classification}

The current regulatory system was legalized in 1940 . It so happens that the vision of children and adolescents historically evolves, making this apparatus outdated and precarious, with rules of procedure inadequate to the current reality, especially for the resolution of problems such as rape of the vulnerable, which, due to social pressure, becomes be denounced a few decades ago, thus lacking qualified professionals to deal with the situation and legalization compatible with the social and cultural reality experienced.

Adhering to this concept, on the initiative of the CPMI on the Sexual Exploitation of Children and Adolescents, the Senate Bill No. 253/04 is determined, which results in the enactment of Law 12,015/09, which entails changes in Title IV of the Code Criminal, such as the modification of the nomenclature to "OfCrimes Against Social Dignity" and entails changes to the penal normative system, starting to highlight the crime as a means of harming the social environment and not just the victim and those involved, highlighting the introduction of a new normative species, Article 217-A of the $\mathrm{CP}$, characterized as the rape of the vulnerable, reaching the year 2009 when it included it in the list of heinous crimes.

The legal asset protected here is the "sexual dignity of children under the age of fourteen, or of the sick or mentally handicapped who has difficulty in discerning the practice of the sexual act" [21]. In this sense, says the magisterium Muñoz Conde [22], mentioned by Bittencourt "more than the freedom of the minor or incapable, which obviously does not exist in these cases, it is intended, in the case of the minor, to protect his future freedom, or rather, the normal evolution and development of his personality, so that when he is an adult he can freely decide his sexual behavior". In this same line of reasoning, argues, Luciane Potter Bitencourt [13]:

In sexual crimes involving children and adolescents, more than sexual freedom, the physical and psychological integrity and dignity of the human person are also violated, as sexuality in children and adolescents, young people whose personalities are still developing, is not can talk about sexual freedom.

That is, the fact that, up to the age of 14 , the child or adolescent or adult who fits the conditions described in the criminal type is not able to decide their sexual freedom, since they do not have psychological maturity and even, physical, to decide for themselves whether or not to have sexual relations. As for the classification of this conduct, we can put it as:

It is a common crime (does not require any special quality or condition of the active subject; the fact that only someone vulnerable can be a passive subject does not qualify it as a specific crime); material (a crime that causes transformation in the external world, that is, it leaves traces); intentional (there is no provision for at fault); in a freeway (can be practiced in any way or means chosen by the active subject); commissive (the nuclear verb implies the practice of an action); instantaneous (the consummation does not extend in time, it is configured at a specific moment); uni subjective (can be committed by a single person); multi-subsistent (the conduct can be divided into several acts, depending on the case)[23].

It can be affirmed, according to Greco [24], that the crime does not admit culpable modality, admitting in this sense the type error regarding the victim's age - the person has a sexual relationship with the victim, believing that she is of a different age than that of the victim. she actually possesses-, which can cause an unusual fact or typify it in the crime of rape in cases where there is violence or serious threat, Art. 213 of the CP. In this typical fact, the special subjective element of the unjust is needed, that is, it falls 
within the typology that Welzel [25] distinguishes as crimes of tendency (voluptuous), or intensified tendency, where the action is involved by a certain mood, (in this case, the desire to have the victim sexually) that is, a purpose of action, whose absence of this will makes its typicality impossible.

It is verified in the law that the criminal agent had the intention of sexually favoring the victim, discarding their willingness to cooperate with the act or not, (since, in this criminal modality, the will of the victim under 14 years of age, or with illness or mental deficiency does not count as a means of assent -the will of these people, here is discarded, the crime subsists even with their consent-), however, they practice the act believing that the victim is of another age, this crime starts its typification when there is the agent's will to perform the act, without this will -animal-, there is no crime.

\section{Criminal Procedure Processing: Children and Adolescents}

In the current procedural system, the work is based on the search for the real truth, that is, on investigating the crime and reprimanding the aggressor, leaving the victim in the background, unconcerned about their re victimization and traumas that may be installed within them.

It would be interesting if the process of communication of the crime of rape of a vulnerable person proceeded with the following legal-procedural procedure: first, the complaint would be made to the Guardianship Council, in accordance with Article 13 of Eca, which says: "The cases of suspicion or confirmation of maltreatment against a child or adolescent shall be mandatorily communicated to the Guardianship Council of the respective location, without prejudice to other legal provisions" and Art. 98 of the aforementioned legal diploma, which expresses: "Art. 98. Measures to protect children and adolescents are applicable whenever the rights recognized in this Law are threatened or violated: I -by action or omission of society or the State; II -for lack, omission or abuse of parents or guardian; III -by reason of their conduct".

According to the ECA, in Art. 136, after investigating the denunciation of the crime, the body of the Guardianship Council is responsible for forwarding to the Public Prosecutor's Office the news that constitutes a criminal offense against the child or adolescent. Concomitantly, the denouncement must be made to the police authority, so that the investigation can be initiated, this is the moment when the vulnerable must be heard, so that they can present their criminological report.

At this point, the victim will be referred to the Forensic Medical Department, to proceed with the expert examinations, whose collected data are forwarded to the Public Ministry, who will hear the child's testimony and forward it to a psychologist expert. In accordance with the ECA [26]:

Whenever factual notice is present that constitutes an administrative or criminal infraction on the rights of the child or adolescent (Art. 136, item IV, of the ECA), as well as, if it proves necessary to file actions for suspension or removal of family power (Art. 136, item XI, of the ECA), regardless of the measures of protection or applicable to the parents (Art.101 and 129 of the ECA), the Guardianship Council will forward or represent the Prosecutor. With the information in hand, the Public Prosecutor's Office will assess the need to file the suspension or dismissal of family power, as well as the adoption of applicable legal measures. By proposing the action, in the civil or even criminal scope, the Public Prosecutor's Office triggers the justice system, starting a new phase in the life of the child or adolescent and their parents.

When the investigation proceeds, in case there is evidence of materiality and authorship, the Public Prosecutor's Office will file a complaint against the perpetrators of the violence. Proceeding then, to the criminal justice system, where again the victim must testify [27].

In this way of seeing the persecutory system, there is a lack of competent professionals to deal with this type of situation, as the child is faced with a room surrounded by strangers, to whom they need to talk about the events and expose themselves, in addition to referring to the child, the professionals do not have enough skill to make them report the events, as the professional needs to be clear, without being rude, and avoid using a vocabulary that is out of the understanding of the vulnerable, and you also need to be sensitive so that you don't feel degraded in the face of a situation that in itself is already embarrassing.

\section{The Problem in the Liabilities' Listing}

From 1990 onwards, the institutional system moved towards a new apparatus for the integral protection of children and adolescents, with a focus on international order, principles and models, in compliance with the Magna Law. However, the lack of in-depth knowledge of these laws, the unpreparedness of legal practitioners, the absence of public policies and the social devaluation of these legislated rights need to be confronted and removed from practice.

Magna Carta presents the possession of an expressly effective legal system; however, it lacks the practical proposition of these laws. The systematic disproportion in the criminal scope in relation to vulnerable taxpayers is verifiable, since active subjects reserve the precincts of a 
specialized police station to act in order to settle and resolve any conflicts, but in the case of vulnerable victims, the themselves, have equal treatment to victims of crimes of any other nature or age, which denotes a methodical inequality, verifiable in art. 201 of the CPP, which deals with the taking of testimony by the victim and art. 202 of the CPP et seq., which deal with witnesses.

Thus, crimes committed against children and youth are judged in the common courts, where they wait in rooms with the other members of the process, family members and the active subject of the crime (the rapist) are included in this list. Which facilitates the victim's bribery or coercion, harming their testimony, and with this the verification of the real truth, unlike the infractions that if committed by young people, are judged in the childhood and adolescence courts, demonstrating an institutional disharmony.

Furthermore, a psychological understanding of the subject is necessary to obtain a positive result, as the interviewer needs to be prepared for the situation, without being involved in a pious way, or being formal to the point of making the inquisition through simple bureaucracy., aware that the taxpayer is the holder of the clarification of the facts, and the investigator is responsible for appropriating this information, a step that is crucial for the process to unfold. In understanding, Maria Fay de Azambuja [28] disposes:

The child's hearing is essentially aimed at producing proof of authorship and materiality, given the few elements that usually guide the process, in order to obtain the abuser's conviction or acquittal, with the child bearing a responsibility for which he is not prepared, due to their peculiar condition as a developing person or, still, under the terms of the Convention, due to their physical, cognitive and psychosocial immaturity.

For Osvaldo Marcón [29], "it is not a matter of momentary well-being or discomfort. On the contrary, they are harmful effects of the health order and the system of social representations that regulate the daily conduct of the child or adolescent." It stands out at this moment, with respect to the Framework Decision of the Council of the European Union of 15.03.2001[30], which constitutes in art. 8, $\mathrm{n}^{\circ} 4$, guidelines to Member States in order to resolve the effects of their testimonies in public hearings, providing protection to juvenile victims, also includes art. 14, No. 1, on the training of people who will be involved in the process or contact with the victim and finally in art. $15, \mathrm{n}^{\circ} 1$, highlighted the need to provide the necessary conditions to reduce the pressure on the victim and prevent secondary victimization.

In consideration Danilo Marcondes de Souza Filho [31], highlights that there must be an analysis regarding the expressions to be used, considering "how, why and by whom" in the choice of sentence formation in accordance with Austin [32], which "proposes the analysis of language as action, the analysis is directed to the speech act and the consequences arising from that speech", so that when using speech consciously, one will have a sharper perception of the phenomena.

For Jorge Trindade [33], the reliability of the reports depends on the procedures adopted by the collector, considering that multiple details can influence the reports, such as the presence of the abuser, the formality of the environment, the coldness of the procedures, causing memory and expressions may be harmed from individual to individual. Therefore, how to proceed in order to resolve these conflicts? What solution to use to obtain the best result with the least possible impact on the victim? How to make justice more human when it is so rigid and formal?

\section{Testimony Project without Damage or Special Testimonial as a Way of Deciting Secondary Victimization}

The Testimony without Damage project was conceived by judge José Antonio Daltoé Cezar, its function is to dissipate the psychological traumas faced by the child-juvenile victim and bring the judiciary closer to the truth of the facts, making possible the enforcement of justice. In understanding, asserts José Antonio Daltoé Cezar [34]:

... It is a child's right to be heard in judicial and administrative proceedings that respect him, and not a mere prerogative of the judicial authority (...), it is proposed to update the national legal system, which at no time, until this date, has taken care of to contextualize the determinations contained in article 227 of the Federal Constitution.

The idea of the project arose from the need for a special procedural system for children, differentiating them from the apparatus of adults according to age and degree of discernment, having understanding with the situation experienced, according to Carla Carvalho Leite [35], the hearing of the victim must be done properly, avoiding the production of secondary harm, which can sometimes be more psychologically harmful to the child than the primary harm caused by the crime.

A pioneer in the idea, the Judge based in the District of Porto Alegre, under the guidance of psychoanalysts Mario Fleig and Conceição Beltrão, inspired by the work of Veleda Dobke, formed a group of interested parties in the area and applied on April 6, 2003, at the 2nd Court of Childhood and Youth of the Central Forum of Porto Alegre the pilot project 
Depoimento Sem Damo, in the following year "the project took on an institutional character sponsored by the Court of Justice of Rio Grande do Sul from the Special Secretariat for Human Rights, supported the project, spreading the practice to other Brazilian states" [36].

In summary, Daltoé Cezar [34] explains as follows:

It is a question of removing them from the formal environment of the courtroom and transferring them to a room specially designed for this purpose, which must be properly connected, by video and audio, to the location where the Magistrate, Prosecutor, Lawyer, defendant and court clerks are located, who can also interact during the testimony (CEZAR, 2007, p. 51).

The project proposes a new way of questioning victims, without causing changes in Brazilian justice, as added by Carla Carvalho Leite [35]:

Once the hearing begins, the testimony takes place in accordance with the procedural rules, that is, the judge first asks the questions and then the parties formulate the questions, which, once granted by the judge, are formulated by the deponent to the deponent. In this case, the judge does it indirectly, as he directs the questions to the professional who has a listening point and the latter, in turn, passes it on to the victim, adapting it to the victim's vocabulary, which [...] becomes possible through technical training.

In agreement, Estefany Cristine A, et al. [37] lectures that, in the production of evidence, it is perfectly feasible to use psychologists in the inquisition, because through their specific knowledge of approach, a comprehensive knowledge about violence and its repercussions on children becomes possible. , as well as contributing to the examination of the credibility of the testimony, and also in the possibility of evaluating the abuser to analyze the probabilities of the same relapse or recovery from the syndrome.

In her acceptance, Ana Beatriz Lumatti [38], argues that the testimony will be held only once during the process, by a person designated by the magistrate and collected in a special room, different from the usual one, since, according to it, the traditional rooms of hearings were produced in order to denote state supremacy over the victim, so that this medium does not have the capacity to integrate with the child victim, causing even greater psychological disorders in children, causing them to shut up, or cry or not yet present a logical and coherent testimony, circumstances that can lead to the aggressor's acquittal, that is, -impunity.

In liaison Luciane Poterr Bitencourt [12] lectures:

The Testimony without Damage pilot project consists of hosting the testimony of the victim of sexual abuse in a room specially set up with audio and video equipment, connected to the courtroom, thus removing the solemn character of the event. The victim is received, before the hearing, in the hallway of the 2nd JIJ floor, by one of the professionals from the interdisciplinary team and promptly forwarded to the special room, without meeting the accused. During the deposition she neither hears nor sees any of the people in the courtroom. Only one professional takes the victim's testimony, that is, a psychologist or social worker, who is members of the interdisciplinary team of the Child and Youth Courts. The judge, the prosecutor, the defender and the accused follow the testimony through the TV system and are able to send questions to the technician, who, as an interlocutor, passes them on to the child or adolescent, in appropriate language". "...the interview is recorded on a CD, which is then attached to the records.

The purpose of this procedure is to "adapt the principles of criminal procedure, especially the adversarial process and broad defense, with the constitutional principles of human dignity and absolute priority in meeting the rights of children and adolescents", according to CEZAR [8]. This project resulted in proposals for the regularization of the systematic, such as Bill 8.045/10, by Jose Sarney, which is being processed in the Senate, as a form of express adaptation to the jurisdictional order.

\section{Participation of Psychologists and Social Assistants in the Liability Inquisition Project}

For Maria Palma Wolff, the inquisition of children and adolescents carried out by the service of psychologists and social workers is developed in three ways:

Reception: this is the first stage, prior to the testimony, when the psychologist or social worker will recognize the victim's personality. Also at this time, the victim will be aware of the procedure of the hearing, and will choose whether or not to be in the presence of the defendant, at this moment the cognitive and affective capacity of the child will also be assessed, and at this point, the cultural level of the child and with this its language (the way it refers to Organs sexual organs, for example), so that the agent knows how to refer to it when questioning it.

Then comes the deposition phase itself, it is the period in which the victim is transferred to the special room, where the interview will be carried out by the designated professional, at this moment the psychological or social study will not be carried out, as it has already been done in the previous stage, but the victim's deponent stage will take place. In an elucidated statement by Veleda Dobke, that in the case of the 
legal operator not having knowledge about the dynamics of the sexual offense, or difficulty in interpreting child language, or not having inquisitive training for the offense itself, it may be possible , appoint an interpreter capable of validly listening to the victim without causing secondary harm. Thus, José Antonio Daltoé Cezar [34] clarifies:

...Of the testimony, which usually lasts between twenty and thirty minutes of uninterrupted recording, the first observation to be made is that it is a preliminary hearing that is held in the current procedural, criminal or civil, through the presidential system - the judge is responsible, exclusively, for initiating and ordering the acts, according to the law, and to decide on the issues that arise during their course -with the technician acting as a facilitator of the child/adolescent's testimony.

Also in relation to the questions passed on by the interpreter, the creator of the project emphasizes the importance of this point to avoid impertinent questions that usually occur in conventional audiences, as in the case of the report evidenced by him in teaching, "I remember a case in which a 12 year old girl had been raped by a guy in his twenties. She was crying, crying, at the hearing, and his lawyer asked a horrible question: he wanted to know if she came. I declined, only she listened; the damage had already been done. It wasn't enough for her to be raped; she was attacked inside the courtroom".

Then, the child, being in a separate room, will participate in the hearing through electronic means, answering questions raised by the interpreter, which protects them from debates or impertinent questions that could distort their mental capacity.

The entire proceeding of the hearing is recorded on a computer and later transferred to a CD that will be attached to the file to serve as evidence. The last phase is called the return, this phase occurs with the end of the hearing, where the psychologist will pass on to those responsible for the minor the relevant aspects of the inquisition, in addition to analyzing the victim's psychological reactions, and the need for evaluative referral of the health network, in this approach, manifests José Antonio Daltoé Cezar [34]:

Unlike what happens when a hearing is held by the system strictly provided for in the procedural rules, in which the victim of sexual abuse or other violence, after the end of the inquiry, is dismissed and no longer maintains any contact with the justice system, The Testimony Without Damage project proposes that the object of listening to the child/ adolescent does not end immediately, as a way to once again value him as a subject of rights and to dispel the idea [sic] that that moment was only a means -the child/adolescent the object -so that the State could achieve the desideratum of a judicial process.

Thus, there is an effective regulatory system, however, with a view to protecting the dignity of human beings so that their life in society is not sacrificed, even after their incidence in a traumatic and violent crime such as rape.

\section{Conclusion}

It is noticeable that the legal circle composed of legal practitioners are aware of social and cultural changes in society, and therefore an archaic and inhibiting procedural system are unacceptable, where the search for real truth is above any kind, including dignity human. Based on Universal Rights and paying attention to differences, projects are being promulgated that aim at an egalitarian right, which values being as a social individual, respecting, therefore, the differences inherent to human beings and their age group.

Regardless of its nomenclature, "Depoimento Sem Damo" or "Special Testimony", what qualifies each one is their concern with the enforcement of justice, based on minimizing the traumas faced by the child. What is proposed with the new method of inquiry is the humanization of justice, based on the Declaration of Human Rights, the Federal Constitution and the ECA. This project calls into question the formality of justice, facing the victim of rape, which in itself already produces enough damage for the vulnerable, who, as seen, since the beginning had been treated as an object, as a minor -"oh, minor", before the legal system.

In line with the advancement of humanity and the cultural evolution developed in recent times, there is a need for the law to walk in social harmony, which is why an outdated precept is unacceptable, such as the treatment performed in a matter of such sensitivity and need for legal intervention, as this judicial attitude generates social insecurity and, therefore, the disharmony of the norm, resulting in the citizen's disbelief with the enforcement of justice.

After all, it is clear that in addition to express laws, there is a need to enforce the rule, and for this purpose, an adequate inquisition is essential, only with an investigation in an equal manner with the victim will it be possible to know the facts. Given this, the qualification of professionals in contact with the taxable person is imperative. It is verifiable based on the established bills, that the legislator is alert with respect to procedural harmony and the egalitarian evolution of humanity, seeking to eliminate the gaps and implement the rights inherent to human beings, in an equal way to equals, and addressing unequal to unequal, starting to see the vulnerable as a subject of rights and in need of judicial protection. 
The method of deposition without damage, as verifiable in the districts where they are used, is perfectly effective and consistent with the legal system, helping to protect the vulnerable individual, providing assistance and security in legal effectiveness. It allows the procedure of due legal process, in addition to promoting victim protection, and through qualified professionals, ensuring that justice is effective. Still, it determines the effectiveness of the norm with the reality imposed -in force- in society. As a result, it seeks the proximity of the legal system with the legal citizen, bringing comfort and a feeling of security, which results in effectively resolved crimes.

\section{References}

1. Article 217-A of CP/40. Having carnal conjunction or performing another libidinous act with a child under 14years old: (Included by Law No. 12.015, of 2009).

2. Penalty -imprisonment, from 8 to $15 y$ ears. (Included by Law No. 12.015 of 2009).

3. $\$ 1$ The person who practices the actions described in the caput with someone who, due to illness or mental deficiency, does not have the necessary discernment to perform the act, or who, for any other reason, cannot resist, shall incur the same penalty. (Included by Law No. 12.015 of 2009).

4. $\S 2$ (VETOED) (Included by Law No. 12.015, of 2009).

5. $\$ 3$ If the conduct results in bodily injury of a serious nature: (Included by Law No. 12.015, of 2009).

6. Penalty imprisonment, from 10 to 20years. (Included by Law No. 12.015 of 2009).

7. §4 If the conduct results in death: (Included by Law No. 12.015 , of 2009)

8. Cezar Roberto B (2013) Criminal Law Treaty, Special Part. $4^{\text {th }}(E d n),. 7^{\text {th }}$ Saraiva, pp: 598.

9. Andre Viana C (2008) Comprehensive Protection Theory: Assumption for Understanding the Rights of Children and Adolescents, pp: 22-42.

10. Penalty -imprisonment, from 12 to 30 years. (Included by Law No. 12.015 of 2009)

11. The penalties provided for in the main section and in $\S 1$, $\S 3$ and $\S 4$ of this article apply regardless of the victim's consent or the fact that she had sexual relations prior to the crime. (Included by Law No. 13.718 of 2018).

12. Luiz Regis M (2010) Criminal Law Course. $9^{\text {th }}$ Revista Dos Tribunais, pp: 809.
13. Luciane Potter B (2009) Secondary Child and Youth Victimization and Intra-Family Sexual Violence: For a Public Policy of Harm Reduction. Lumen Juris.

14. Julio Fabbrini M, Fabbrini RN (2011) Criminal Law Manual: Special Part Arts. 121 to 234-B of the CP. $28^{\text {th }}$ (Edn.), Atlas.

15. (1941) Brazilian Criminal Procedure Code. Decree-Law No. 3.689 of 10.03. BRAZIL.

16. (1988) Constitution of the Federative Republic of Brazil.

17. (1940) Brazilian Criminal Code. Decree-Law No. 2,848 of 12.07 .

18. (2002) Brazilian Civil Code. Law 10.406.

19. (1990) Child and Adolescent Statute. Federal Law No. 8.069 of 13.07 .

20. State Judicial Organization Code. Law No. 7356/80.

21. Heinous Crimes Act. Law No. 8.072/90.

22. Law on Special Civil and Criminal Courts. Law No. 9099/95.

23. (2009) Criminal Code. Law No. 12.015.

24. CIJ-Children and Youth Coordination: Special Testimony for Children and Adolescents.

25. BRAGA, Mariana Innovation and Judicial Administration Center.

26. (2013) IBDFAM.

27. (2013) Legal Adviser.

28. (2012) Legal Adviser.

29. (2013) Jurists Your Legal Portal.

30. De Castro AK (2021) The Statement without Damage in Analysis: The Perspective of Psychology.

31. Claudia B (2021) Intrafamily Children's Sexual Violence: The Revitimization of the Child and Adolescent Victims of Abuse.

32. Caroline da S (2008) Applicability of the Statement without Damage.

33. Cirqueira de SJ (2021) The Implementation of the Statement without Damage in the Brazilian Judicial System.

34. Marina Dantas P, Marie Cabral L, Ataide Cardoso L, Arruda 
Rodrigues J (2009) The new criminal type of vulnerable rape and its repercussions on our legal system.

35. (1985) Virtual Library of Human Rights. University of São Paulo-USP. Declaration of Basic Principles of Justice Relating to Victims of Crime and Abuse of Power.

36. Clarissa De A, Mattar Yunes MA, Habigzang L; Helena Koller S (2021) Extrafamilial sexual abuse: perceptions of mothers of victims.

37. Estefany Cristine A, Nessyane Messias S, Liza H (2014) Intra-Family Violence against Children and Adolescents: A Necessary Discussion 8(S 1): 2498-2506.

38. (2014) Historical-Normative Evolution of Youth Criminal Protection and Responsibility in Brazil. NetSaber Articles. 